\title{
Application of Pain Scale Assessment in Patients Attached Mechanical Ventilator in Intensive Care Unit
}

\author{
Barkah Waladani ${ }^{1, *}$ Isma Yuniar ${ }^{2}$ Endah Setianingsih ${ }^{3}$ Naura Nazhifah Rahmah ${ }^{4}$
}

Indah Yunita $^{5}$

${ }^{1,2,3}$ Muhammadiyah Health Science Institute of Gombong
${ }^{4,5}$ Bachelor Nursing Program Muhammadiyah Health Science Institute of Gombong
${ }^{*}$ Corresponding author. Email: barkah.waladani@gmail.com

\begin{abstract}
Special equipment in Intensive Care Unit such as the installation of mechanical ventilation causes the patient to be unable to express the condition he feels, one of which is pain. This study aims to determine the suitability of pain assessment using Critical Pain Observation Tool (CPOT) and Non Verbal Pain Scale (NVPS) in Intensive Care Unit (ICU). This study used a descriptive analytic research method with a crosectional approach with 50 patient. The results of the measurement of pain at rest showed that the patients experienced: no pain as much as 17 (34\%), 19 mild pain $(38 \%)$, moderate pain $7(14 \%)$, severe pain $6(12 \%)$, and very severe pain $1(2 \%)$. Patients experiencing pain were measured using NVPS at positioning and resting. The results of the measurement of pain during positioning showed that the patient experienced: no pain as much as $9(18 \%)$, moderate pain $35(70 \%)$, and severe pain $6(12 \%)$. The results of the measurement of pain at rest showed that the patients experienced: no pain as much as $25(50 \%)$, moderate pain 22 (44\%), and severe pain $3(6 \%)$. CPOT and NVPS can be used to assess the pain experienced by critical patents with mechanical ventilator. These instruments have a good correlation level for measuring the pain scale at rest and positioning.
\end{abstract}

Keywords: Intensive Care Unit, Pain Scale, Ventilator

\section{BACKGROUND}

Intensive Care Unit (ICU) is a unit that serves patients with serious to life-threatening illnesses who require special monitoring and assistance. Special equipment such as the installation of mechanical ventilation causes the patient to be unable to express the condition he feels, one of which is pain [1]. In contrast to the condition of adult patients in the Intensive Care Unit (ICU), patients have difficulty identifying and evaluating pain due to limited abilities due to mechanical ventilation and intubation [2].

According to the American Association of Cultural Care Nurses, as many as $30 \%$ of patients in a resting state experience pain and 50\% during routine care in the ICU. As a result of altered levels of consciousness, sedation or sedation factors, or the installation of mechanical ventilation, many ICU adult patients are unable to independently report pain [3], [4]. The Behavioral Pain Scale (BPS) is the common tool used in the intensive care setting which can be used. But, the Critical Pain Observation Tool (CPOT) has not been used extensively in the hospital [5]. Thus, the efficacy of this tool needs to be examine. There are pain measuring instruments studied, such as BPS, CPOT and NPVS had the best scores in quality assessments [6], [7]. BPS and CPOT measuring instruments have many, namely measuring instruments with one dimension and have been tested in many areas of critical nursing setting. In BPS and CPOT all pain evaluation are based on signs of behaviour [8]. The focus of BPS and CPOT is on the changes resulting form increase in pain intensity in both parameters [9], [10]. In contrast to CPOT and BPS, NVPS uses body movements in a similar way to BPS and CPOT, but for facial expression the assessment depends on the duration of the expression that indicates pain during the measurement period [11]. BPS and CPOT assessments can measure differences in pain intensity at rest with positioning, can assess pain and improve pain management in patients with critical conditions [12], [13]. Intensive Care Unit in Muhammadiyah Hospital, itself for pain assessment in patients with critical conditions does not yet exist, so researchers are interested in examining the effectiveness of CPOT and NVPS pain assessments at the PKU Muhammadiyah Gombong ICU. This study aims to determine the suitability of pain assessment using CPOT and NVPS in the ICU.

\section{METHOD}

This study used a descriptive analytic research method with a crosectional approach. This study identified pain measurements using the CPOT and 
NVPS assessments in mechanically ventilated ICU patients. The sampling technique used non-probability sampling through a consecutive sampling approach. The sample were determined based on the criteria for patient treated in the ICU and installed with mechanical ventilator in 5-7 days, age more than 18 years, somnolent and stupor consciousness level and hemodynamically stable and not patients wid diagnosed brain stem death, totaling 50 patient. The data were analyzed using the correlation test and the suitable test with kappa to see suitability of the pain assessment measuring instrument used to assess the level of pain in patient on ventilator.

\section{RESULT}

Data on patients who experienced pain were measured using CPOT at the time of positioning and at rest. The results of the measurement of pain at rest showed that the patients experienced: no pain as much as $17(34 \%), 19$ mild pain (38\%), moderate pain 7 $(14 \%)$, severe pain $6(12 \%)$, and very severe pain 1 (2\%). Patients experiencing pain were measured using NVPS at positioning and resting. The results of the measurement of pain during positioning showed that the patient experienced: no pain as much as $9(18 \%)$, moderate pain $35(70 \%)$, and severe pain $6(12 \%)$. The results of the measurement of pain at rest showed that the patients experienced: no pain as much as $25(50 \%)$, moderate pain $22(44 \%)$, and severe pain $3(6 \%)$.

The Spearman correlation value of 0.340 indicates that the direction of the correlation is positive with weak correlation strength. This indicates that the high and low NVPS measurement results in the resting condition have a weak correlation with the high and low NVPS measurement results in the positioning condition. The Spearman correlation value of 0.639 indicates that the direction of the correlation is positive with strong correlation strength. Thus, this shows that the high and low CPOT measurement results in the resting condition have a strong correlation with the high and low CPOT measurement results in the positioning condition.

\section{DISCUSSION}

The results of the correlation test between resting NVPS and CPOT positioning obtained a correlation value of 0.319 , this indicates that NVPS measurement results in the resting have a weak correlation with the high CPOT measurement results in the positioning condition. In the correlation test between NVPS Positioning and resting CPOT, the correlation value is 0.564 , indicating that the direction of the correlation is

Table 1. Pain Assessment with CPOT and NVPS at the time of positioning and rest

\begin{tabular}{|c|c|c|c|c|}
\hline Scale & Positioning & Percentage & Rest & Percentage \\
\hline \multicolumn{5}{|l|}{ СРОТ } \\
\hline No Pain & 7 & 14 & 17 & 34 \\
\hline Mild & 20 & 40 & 19 & 38 \\
\hline Moderate & 12 & 24 & 7 & 14 \\
\hline Severe & 7 & 14 & 6 & 12 \\
\hline Very Severe & 4 & 8 & 1 & 2 \\
\hline \multicolumn{5}{|l|}{ NVPS } \\
\hline No Pain & 9 & 18 & 25 & 50 \\
\hline Moderate & 35 & 70 & 22 & 44 \\
\hline
\end{tabular}

condition using kappa

\begin{tabular}{|c|c|c|c|c|}
\hline \multirow{2}{*}{ Scale } & \multicolumn{2}{c|}{ NVPS } & \multicolumn{2}{c|}{ CPOT } \\
\cline { 2 - 5 } & Rest & Positioning & Rest & Positioning \\
\hline NVPS & & & & \\
\hline Rest & 1,00 & 0,34 & $0,319(\mathrm{p}=0,016)$ & \\
\hline Positioning & & 1,00 & 0,363 & 0,564 \\
\hline CPOT & & & & $0,639(\mathrm{p}=0,000)$ \\
\hline Rest & & & 1,00 & 1,00 \\
\hline Positioning & & & 0,567 & \\
\hline
\end{tabular}


positive with moderate correlation strength. Thus, this indicates that the high and low CPOT measurement results in the resting condition are moderately correlated with the high and low NVPS measurement results in the positioning condition.

Based on the correlation test between the NVPS measuring instrument and the CPOT measuring instrument at rest, the $\mathrm{p}$ value was obtained $=0.016$, which indicates that the correlation of the measurement results using the NVPS and CPOT measuring instruments was significant $(\mathrm{p}<0.05)$. The Spearman correlation value on NVPS-CPOT at resting conditions is 0.319 indicating that the direction of the correlation is positive with weak correlation strength. In the correlation test between the NVPS measuring instrument and the CPOT measuring instrument when positioning, the value of $p=0.000$ was obtained, which indicates that the correlation of the measurement results using the NVPS and CPOT measuring instruments was significant $(p<0.05)$. The Spearman correlation value on the NVPS-CPOT at the positioning condition is 0.564 indicating that the direction of the correlation is positive with moderate correlation strength. Thus, this indicates that the high and the low of the measurement results using the CPOT measuring instrument have a very moderate correlation with the high and low measurement results using the NVPS measuring instrument in the same conditions.

The results of the suitability test (kappa test) for measuring pain scale assessment using CPOT and NVPS. The results for the CPOT measuring instrument with a $\mathrm{p}$ value of $0.009(<0.05)$ were significant with a kappa value of 0.915 indicating a very good level of agreement. The results for the NVPS measuring instrument with a $\mathrm{p}$ value of 0.061 (>0.05) were insignificant with a kappa value of 0.381 indicating a fairly good level of agreement.

The results of this study indicate that the two pain measuring instruments, namely CPOT and NVPS, are compatible in assessing the level of pain in patients who are attached to a ventilator in the intensive room who are unable to report pain verbally. This can be shown from the results of the analysis of the CPOT measuring instrument at rest and which positioning is significant with a value $(\mathrm{p}=0.009)$. These results explain that the CPOT gauge is able to measure the level of pain in patients on a ventilator who are unable to report pain during rest or positioning. In patients who are treated in the intensive care unit, pain is a common symptom that often appears during treatment (positioning) or at rest [14]. Need any indicators in assessing the non-verbal pain response are needed, so that behavior that leads to pain can be observed using CPOT. It is recommended to use the CPOT pain gauge because it can help nurses assess the patient's pain response non-verbally [15].

The results of the correlation analysis test using the Spearman on the NVPS measuring instrument at rest with positioning showed a low correlation level $(0.340)$. This value indicates the high level of pain in a person at rest using NVPS. It will not necessarily indicate a higher level of pain during positioning. Pain is individual, which causes a different pain response. The results of the correlation analysis test on the CPOT measuring instrument at rest and positioning show that the correlation level is moderate $(0.564)$. This shows that the high level of pain in a person when resting using CPOT will show more pain levels during positioning. Pain that is felt by patients who are put on a ventilator in the intensive room includes both invasive and non-invasive treatment, namely changes in position [16].

Based on the analysis of the suitability test (kappa) for the CPOT and NVPS measuring instruments at rest and positioning, the values are different. The value for the CPOT gauge (Kappa $=0.915)$ leads to a very strong agreement. Judging from the two suitability values, it shows that the two measuring instruments can be used to non-verbally measure the pain level of a critical patient on a ventilator [17], [18]. Convey that from 3 measuring instruments for FLACC, NVPS and CPOT pain assessment, the highest agreement value is obtained on the CPOT pain measurement tool. The nurse finds it easy to judge because a clear description of each indicator allows assessing consistently and in a timely manner [19].

The CPOT gauge has 5 indicators (facial expression, body movement, ventilator alarm activity, speaking if the patient is extubated, and muscle tension) measurements equipped with each indicator describing the condition with a different score where there is a clearer description of each indicator [20]. Indicators of facial expression, muscle tension and ventilator alarm activity are important indicators in assessing pain response in patients on ventilator [21]. These criteria make it easier to assess patients in assessing the level of pain they feel. the CPOT measurement tool has significant results that can be used to measure the pain response of patients who are attached to a ventilator in the intensive room when resting and positioning. The facial expression indicator scores well in determining the pain scale [22].

The value of the NVPS measuring instrument $($ Kappa $=0.381)$ leads to sufficient agreement. In NVPS testing the total correlation showed moderate correlation for most of the items. The physiological correlation between II and NVPS is quite low. The NVPS measuring instrument has 5 measurement 
indicators which are explained in each score point to explain the conditions experienced [23]. Indicators for the assessment of patients with mechanical ventilation are not included, so that in assessing patients who are mechanically ventilated, we can only see the physiology and respiratory status of the patient. NVPS includes facial expressions, activity or movement, body position, physiology, and respiratory status. NVPS uses physiological indicators such as blood pressure, heart rate, and respiratory rate in addition to visual cues to indicate the patient's pain level [24], [25]. Physiological indicators can help to accurately assess pain in nonverbal patients but caregivers should be careful when evaluating them for pain assessment purposes. Other triggers such as agitation, anxiety, or even infection can cause changes in physiological processes.

\section{CONCLUSION}

CPOT and NVPS can be used to assess the pain experienced by critical patents with mechanical ventilator. These instruments have a good correlation level for measuring the pain scale at rest and positioning. However CPOT has a better agreement level than NVPS does.

\section{ACKNOWLEDGMENTS}

The research is limited to measuring the pain level value of a patient with a ventilator without looking at the patient's characteristics, so it was unable to relate to the pain value obtained. NVPS measuring instruments are very rarely used in Indonesia and abroad, so the strengthening of the analysis is lacking.

\section{REFFERENCES}

[1] C. Arbour and C. Gélinas, "Are vital signs valid indicators for the assessment of pain in postoperative cardiac surgery ICU adults?," Intensive Crit. Care Nurs., 2010, doi: 10.1016/j.iccn.2009.11.003.

[2] C. H. Cade, "Clinical tools for the assessment of pain in sedated critically ill adults.," Nursing in critical care. 2008, doi: 10.1111/j.14785153.2008.00294.x.

[3] C. Gélinas, K. Puntillo, A. Joffe, and J. Barr, “A validated approach to evaluating psychometric properties of pain assessment tools for use in nonverbal critically ill adults," Semin. Respir. Crit. Care Med., 2013, doi: 10.1055/s-00331342970.

[4] A. A. Asadi-Noghabi, M. Gholizadeh, M. Zolfaghari, A. Mehran, and M. Sohrabi, "Nurses use of critical care pain observational tool in patients with low consciousness," Oman Med. J., 2015, doi: 10.5001/omj.2015.55.
[5] K. Herr, P. J. Coyne, M. McCaffery, R. Manworren, and S. Merkel, "Pain Assessment in the Patient Unable to Self-Report: Position Statement with Clinical Practice Recommendations," Pain Manag. Nurs., 2011, doi: 10.1016/j.pmn.2011.10.002.

[6] Y. Aïssaoui, A. A. Zeggwagh, A. Zekraoui, K. Abidi, and R. Abouqal, "Validation of a behavioral pain scale in critically ill, sedated, and mechanically ventilated patients," Anesth. Analg., 2005, doi: 10.1213/01.ANE.0000182331.68722.FF.

[7] B. F. Olsen, T. Rustøen, L. Sandvik, M. Jacobsen, and B. T. Valeberg, "Results of implementing a pain management algorithm in intensive care unit patients: The impact on pain assessment, length of stay, and duration of ventilation," J. Crit. Care, 2016, doi: 10.1016/j.jcrc.2016.07.011.

[8] L. M. J. Hochstenbach, A. M. Courtens, S. M. G. Zwakhalen, J. Vermeulen, M. van Kleef, and L. P. de Witte, "Co-creative development of an eHealth nursing intervention: Self-management support for outpatients with cancer pain," Appl. Nurs. Res., 2017, doi: 10.1016/j.apnr.2017.03.004.

[9] J. Topolovec-Vranic, S. Canzian, J. Innis, M. A. Pollmann-Mudryj, A. W. McFarlan, and A. J. Baker, "Patient satisfaction and documentation of pain assessments and management after implementing the adult nonverbal pain scale," Am. J. Crit. Care, 2010, doi: 10.4037/ajcc2010247.

[10] D. Li, K. Puntillo, and C. Miaskowski, "A Review of Objective Pain Measures for Use With Critical Care Adult Patients Unable to SelfReport," Journal of Pain. 2008, doi 10.1016/j.jpain.2007.08.009.

[11] J. Young, J. Siffleet, S. Nikoletti, and T. Shaw, "Use of a Behavioural Pain Scale to assess pain in ventilated, unconscious and/or sedated patients," Intensive Crit. Care Nurs., 2006, doi: 10.1016/j.iccn.2005.04.004.

[12] A. M. Kabes, J. K. Graves, and J. Norris, "Further validation of the nonverbal pain scale in intensive care patients," Crit. Care Nurse, 2009, doi: $10.4037 / \operatorname{ccn} 2009992$.

[13] L. Marmo and S. Fowler, "Pain Assessment Tool in the Critically Ill Post-Open Heart Surgery Patient Population," Pain Manag. Nurs., 2010, doi: 10.1016/j.pmn.2009.05.007.

[14] K. Kotfis, M. Zegan-Baraska, L. SzydLowski, M. Ukowski, and E. W. Ely, "Methods of pain assessment in adult intensive care unit patientsPolish version of the CPOT (Critical Care Pain Observation Tool) and BPS (Behavioral Pain 
Scale)," Anaesthesiology Intensive Therapy. 2017, doi: 10.5603/AIT.2017.0010.

[15] A. Prawesti Priambodo, K. Ibrahim, and N. N, "Pengkajian Nyeri pada Pasien Kritis dengan Menggunakan Critical Pain Observation Tool(CPOT) di Intensive Care Unit(ICU)," J. Keperawatan Padjadjaran, 2016, doi: 10.24198/jkp.v4n2.6.

[16] K. A. Puntillo et al., "Determinants of procedural pain intensity in the intensive care unit: The Europain ${ }^{\circledR}$ study," Am. J. Respir. Crit. Care Med., 2014, doi: 10.1164/rccm.201306-1174OC.

[17] P. Severgnini, P. Pelosi, E. Contino, E. Serafinelli, R. Novario, and M. Chiaranda, "Accuracy of Critical Care Pain Observation Tool and Behavioral Pain Scale to assess pain in critically ill conscious and unconscious patients: Prospective, observational study," J. Intensive Care, 2016, doi: 10.1186/s40560-016-0192-x.

[18] J. Barr et al., "Clinical practice guidelines for the management of pain, agitation, and delirium in adult patients in the intensive care unit," Crit. Care Med., 2013, doi: 10.1097/CCM.0b013e3182783b72.

[19] C. Gélinas and C. Johnston, "Pain assessment in the critically ill ventilated adult: Validation of the critical-care pain observation tool and physiologic indicators," Clin. J. Pain, 2007, doi: 10.1097/AJP.0b013e31806a23fb.

[20] M. Stites, "Observational pain scales in critically ill adults," Crit. Care Nurse, 2013, doi: $10.4037 / \operatorname{ccn} 2013804$.

[21] S. J. G. M. Ahlers, A. M. Van Der Veen, M. Van Dijk, D. Tibboel, and C. A. J. Knibbe, "The use of the behavioral pain scale to assess pain in conscious sedated patients," Anesth. Analg., 2010, doi: 10.1213/ANE.0b013e3181c3119e.

[22] S. Rijkenberg, W. Stilma, R. J. Bosman, N. J. van der Meer, and P. H. J. van der Voort, "Pain Measurement in Mechanically Ventilated Patients After Cardiac Surgery: Comparison of the Behavioral Pain Scale (BPS) and the CriticalCare Pain Observation Tool (CPOT)," J. Cardiothorac. Vasc. Anesth., 2017, doi: 10.1053/j.jvca.2017.03.013.

[23] M. A. Rahu, M. J. Grap, P. Ferguson, P. Joseph, S. Sherman, and R. K. Elswick, "Validity and sensitivity of 6 pain scales in critically ill, intubated adults," Am. J. Crit. Care, 2015, doi: 10.4037/ajcc2015832.

[24] R. Aantaa, S. M. Pudas-Tähkä, A. Axelin, V. Lund, and S. Salanterä, "Pain assessment tools for unconscious or sedated intensive care patients: A systematic review," J. Adv. Nurs., 2009, doi: 10.1111/j.1365-2648.2008.04947.x.
[25] I. Randen, A. Lerdal, and I. T. Bjørk, "Nurses' perceptions of unpleasant symptoms and signs in ventilated and sedated patients," Nurs. Crit. Care, 2013, doi: 10.1111/nicc.12012. 